\title{
Evaluation of Distributed Generation Access to Distribution Network Considering Reactive Power Optimization
}

\author{
Shaotang Xie, Ruiming Fang* and Binbin Chen \\ School of Information Science and Engineering, Huaqiao University, Xiamen 361021 \\ ${ }^{*}$ Corresponding author
}

\begin{abstract}
The operation of distribution network will be greatly affected when distributed generation (DG) is accessed to the network. The degree of influence is closely related to the location and capacity of distributed generation. Therefore, it is of great significance to evaluate the consequence of installing distributed generation to distribution network. This research was carried out from the perspective of reactive power optimization, and the evaluation was performed by super-efficiency data envelopment analysis (DEA). The research is expected to reduce the active power loss of distribution network, to reduce the voltage offset and to make the program more economical. The proposed method could objectively sort the different schemes of DG access to distribution network. Finally, an example was given to show that the proposed method can rank the efficiency values of the evaluation scheme and select the optimal scheme, which is feasible in engineering application.
\end{abstract}

Keywords-distributed generation; distribution network; evaluation method; reactive power optimization; super-efficiency $D E A$

\section{INTRODUCTION}

If the access location and capacity of distributed generation are reasonable, it can improve the power quality of distribution network, reduce the active loss of the system and improve the reliability and economy of distribution network [1-3]. Many scholars have carried out in-depth research and analysis of this topic. Literature [4] presented a multi-objective decision model for the location and capacity of distributed generation, which was established on the basis of considering network loss, voltage quality and current quality. DG optimization model proposed by [5] did not take into account the economy and efficiency of the program, and has some limitations. Literature [6] presented a optimization model to optimize the DG capacity and installation location, where the three important indexes were taken into account, i.e. active power loss, voltage improvement and environmental improvement. A fuzzy adaptive particle swarm optimization method was proposed in [7] to solve the problem of location and capacity of distributed generation. The optimal scheme of distributed generation was obtained by using network loss as the objective function. At present, the research on the evaluation method of distributed generation access to distribution network lacks further consideration of reactive power optimization. In order to reduce the active power loss of distribution network, to reduce the voltage offset and to make the scheme more economical, a new evaluation method was proposed in this paper. From the perspective of reactive power optimization, the superefficiency data envelope analysis (DEA) method was applied to the evaluation of distributed generation access to distribution network. The proposed method results in a more objective and comprehensive evaluation of the scheme.

\section{REACTIVE POWER OPTIMIZATION OF DG ACCESS TO DISTRIBUTION NETWORK}

\section{A. Objective Function}

The objective function of reactive power optimization, including the active power loss $f_{1}$ and the voltage offset $f_{2}$ of distribution network, is expressed as follows:

$$
\begin{aligned}
& \min f_{1}=\sum_{i, j \in N} G_{i j}\left[U_{i}^{2}+U_{j}^{2}-2 U_{i} U_{j} \cos \theta_{i j}\right] \\
& \min f_{2}=\sum_{i=1}^{N}\left(\frac{U_{i}-U_{i}^{\text {spec }}}{\Delta U_{i}^{\max }}\right)^{2}
\end{aligned}
$$

In (1) and (2), $\Delta U_{i}^{\max }$ is the maximum allowable voltage offset value for node $i . U_{i}^{\text {spec }}$ is the expected voltage amplitude for node $i$.

The total objective function of reactive power optimization of distribution network is expressed as follow:

$$
\min f=\omega_{1} f_{1}+\omega_{2} f_{2}
$$

In (3), $f$ is the total objective function of reactive power optimization, $\omega_{1}$ and $\omega_{2}$ are the weight and $\omega_{1}+\omega_{2}=1$.

\section{B. Constraint Condition}

The balance of each node about active power and reactive power are as follows[8]:

$$
P_{i}=U_{i} \sum_{j \in N} U_{j}\left(G_{i j} \cos \theta_{i j}+B_{i j} \sin \theta_{i j}\right)
$$




$$
Q_{i}=U_{i} \sum_{j \in N} U_{j}\left(G_{i j} \sin \theta_{i j}-B_{i j} \cos \theta_{i j}\right)
$$

The control variables are constrained as follows:

$$
\begin{gathered}
T_{\text {min }}<T<T_{\text {max }} \\
Q_{C \text {.min }}<Q_{C}<Q_{C \text {.max }} \\
Q_{D G \text {.min }}<Q_{D G}<Q_{D G \text { max }}
\end{gathered}
$$

In (6)-(8), $T$ is the position of the on-load tap changer's tap. $Q_{C}$ is the reactive capacity of the shunt capacitor. $Q_{D G}$ is the reactive power output of DG.

\section{Bacterial Colony Optimization}

In this paper, bacterial colony optimization (BCO) was used in the reactive power optimization algorithm. The optimal solution of the target was performed by simulating the growth process of individual bacteria and colony[9].

In the bacterial colony optimization algorithm, the update formula of the individual walking of the bacteria is as follows:

$$
\begin{gathered}
V_{k+1}=\alpha V_{k}+r_{1} \text { rand } \cdot\left(f_{\text {best }}-P_{k}\right)+r_{2} \text { rand } \cdot\left(g_{\text {best }}-P_{\mathrm{k}}\right) \\
P_{k+1}=P_{k}+V_{k+1}
\end{gathered}
$$

In (9) and (10), $V_{k}$ is the direction of the bacterial individual going through the iteration, $P_{k}$ stands for the position of the bacterial individual at the iteration, $f_{\text {best }}$ represents the optimal position of the individual last time and $g_{\text {best }}$ represents the global optimal position of the current colony.

When the objective function value of individuals in the space position was not better than the previous objective function value, it suggested that the bacteria had not reached the area of nutrient enrichment. The formula for updating the individual position is as follow:

$$
P_{k+1}=P_{k}+\text { Rrandn }
$$

In (11), $R$ represents the search radius of the individual bacteria, randn represents the random number on $(-1,1)$.

\section{EVAlUAtion OF Distributed GENERATION ACCESS TO DisTRIBUTION NETWORK CONSIDERING REACTIVE POWER OPTIMIZATION}

\section{A. Super-Efficiency data Envelopment Analysis}

The data envelopment analysis (DEA) was achieved by keeping the decision-making unit (DMU) of the input and output unchanged. Mathematical programming DMU projection was adopted to the DEA frontier, to evaluate the relative effectiveness of these DEA in the decision making unit by comparing the deviation [10-12].The traditional CCR model and BCC model have some limitations, as they cannot be further distinguished from the evaluation scheme of the efficiency value greater than 1 .The super-efficiency model can be used to solve the problem of the sample efficiency in DEA model [13].

The super-efficient DEA mathematical model is as follows:

$$
\left\{\begin{array}{l}
\text { s.t. } \sum_{j=1, j \neq k}^{n} X_{j} \lambda_{j}+S^{-}=\theta X_{k} \\
\sum_{j=1, j \neq k}^{n} Y_{j} \lambda_{j}-S^{+}=Y_{k} \\
\lambda \geq 0 \\
S^{-} \geq 0, S^{+} \geq 0
\end{array}\right.
$$

\section{B. Evaluation Method}

In order to reduce the active power loss of distribution network, to reduce the voltage offset and to make the program more economical, this research was conducted from the perspective of reactive power optimization. The bacterial colony optimization algorithm was used to calculate the reactive power optimization results of DG from different nodes respectively. Combining with data envelopment analysis method, then the four indexes, i.e. the reactive power capacity of the shunt capacitor, the voltage ratio of the on-load tap changer, the reactive power output of the DG and the capacity of DG were used as the input indexes of the scheme. The voltage offset of distribution network and active power loss were required to make the reciprocal as the output index of the scheme. The efficiencies of the different schemes were calculated by the super-efficiency DEA method. Therefore, the DG access node and capacity were analyzed and evaluated. The higher the efficiency value of the scheme, the higher the benefit value of the output index relative to the input index will be. This has achieved the purpose of reducing costs. In this way, an objective analysis of the scheme was carried out, and the most efficient scheme was the optimal scheme of DG access to distribution network. The idea of the method is shown in Figure 1, where the method's six steps are presented. 


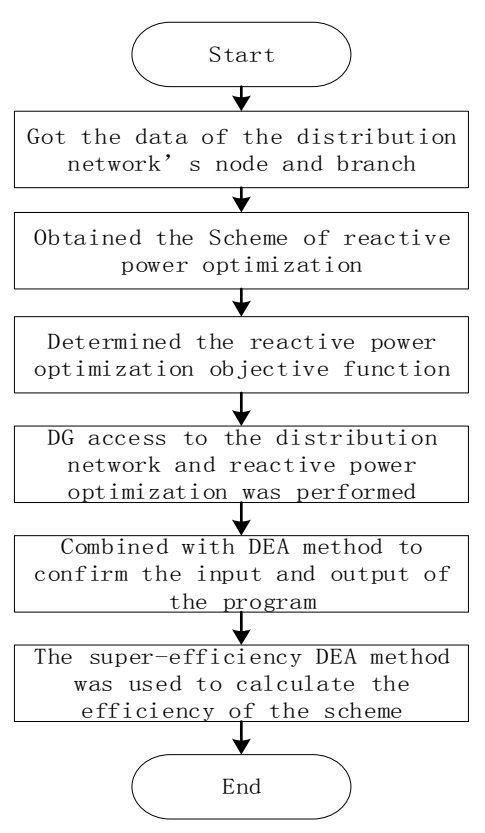

FIGURE I. EVALUATION METHOD

The evaluation index system of the scheme is shown in Figure 2. The index system consists of four input indexes and two output indexes.

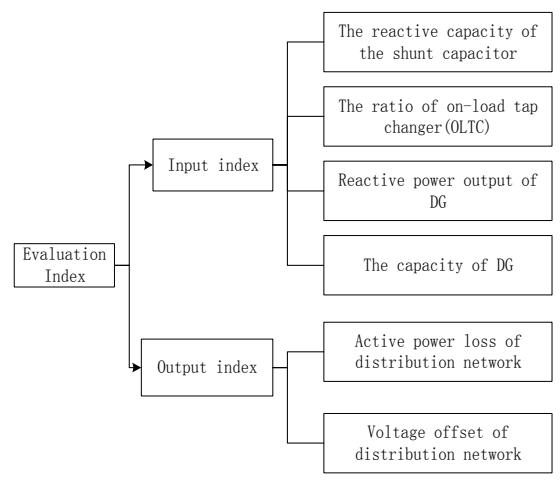

FIGURE II. THE EVALUATION INDEX SYSTEM OF THE SCHEME

\section{CASE STUDY}

In this part, IEEE 33 was used as the test system, shown in Figure 3. In this example, the on-load tap changer was added between nodes 1 and 2. The transformer voltage ratio is $0.9 \sim$ 1.1 , with the step of $1.25 \%$. The capacitor group was connected in parallel at the node 31, and the shunt capacitor capacity can be $100 \mathrm{kVar} \times 10$. In the distribution network, select the number 2, 6, 10, 14 and 18 as the DG access node for analysis. DG capacity range is $0.5 \sim 1.5 \mathrm{MW}$. DG reactive power output range is $-100 \sim 500 \mathrm{kVar}$. Then, the reactive power optimization is carried out under different conditions.

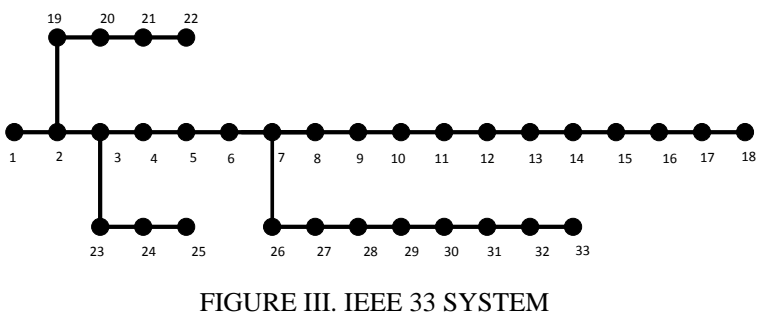

In this example, the simulation results of reactive power optimization could be obtained where DG was accessed from nodes 2, 6, 10, 14 and 18 to distribution network respectively. The distribution network active power loss and voltage offset are shown in Table 1.

TABLE I. ACTIVE POWER LOSS AND VOLTAGE OFFSET

\begin{tabular}{|c|c|c|c|}
\hline Number & Access node & $\begin{array}{l}\text { Active power loss / } \\
\text { MW }\end{array}$ & Voltage offset \\
\hline DMU1 & 2 & 0.1731 & 0.2422 \\
\hline DMU2 & 6 & 0.1282 & 0.1374 \\
\hline DMU3 & 8 & 0.1257 & 0.1014 \\
\hline DMU4 & 14 & 0.1163 & 0.0781 \\
\hline DMU5 & 18 & 0.1302 & 0.0818 \\
\hline
\end{tabular}

The simulation results are shown in Figure 4 and Figure 5.

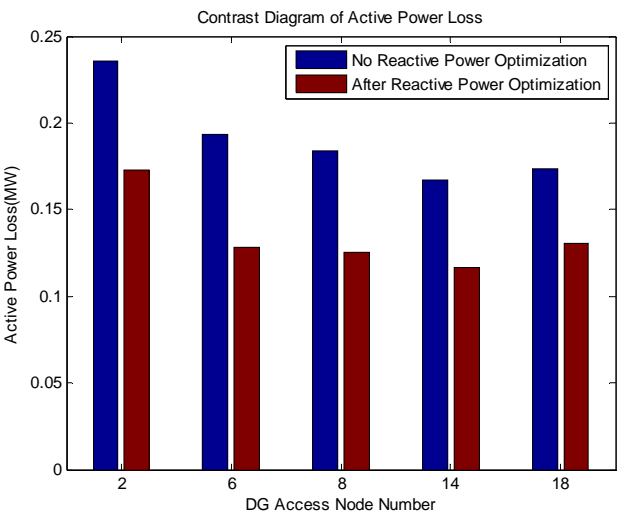

FIGURE IV. COMPARISON OF ACTIVE POWER LOSS

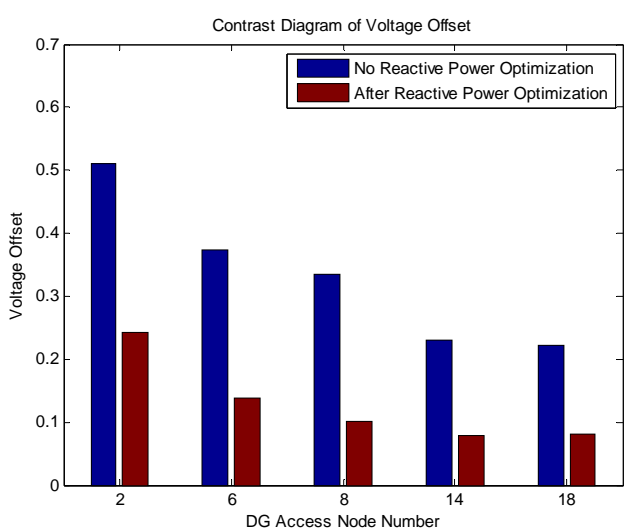

FIGURE V. COMPARISON OF VOLTAGE OFFSET 
As shown in Figure 4 and Figure 5, after the reactive power optimization, the active power loss and voltage offset have changed greatly. In engineering, reactive power optimization is an important issue. Therefore, in the evaluation of distributed generation access to distribution network, the reactive power optimization was taken into account, which could make the evaluation results more objective.

The efficiency values of different schemes were calculated by the super-efficiency DEA. The results are shown in Table 2.

TABLE II. EFFICIENCY VALUES OF SUPER-EFFICIENCY DEA

\begin{tabular}{|c|c|c|}
\hline Number & Access node & Efficiency values \\
\hline DMU1 & 2 & 0.7137 \\
\hline DMU2 & 6 & 0.9155 \\
\hline DMU3 & 8 & 0.9280 \\
\hline DMU4 & 14 & 1.2414 \\
\hline DMU5 & 18 & 1.1463 \\
\hline
\end{tabular}

Through the analysis of Table 2, the scheme efficiency values of the reactive power optimization results accessed by DG from node 14 are the highest among the five nodes for reference. The input of the scheme is the highest degree of effective utilization relative to the output, so node 14 is the optimal access node in these five nodes. According to the results of the super-efficiency DEA, these five schemes were ordered by DMU4 $>$ DMU5 $>$ DMU3 $>$ DMU2 $>$ DMU1. DMU4 is the best scheme and DMU1 is the worst scheme. According to the simulation results, the selected DG capacity is $0.7 \mathrm{MW}$, and the access location is made at node 14 , which is the optimal scheme for the five evaluation schemes.

The scheme in the example was evaluated by the method of [14] and the results are shown in Table 3. According to Table 3, the ranking of the five schemes is DMU5 $>$ DMU4> DMU3 $>$ DMU2 $>$ DMU1. The method of [14] lacks the consideration of the efficiency value of the scheme, that is, the economic consideration. The method of this paper is more comprehensive and the evaluation result is different from the method of [14]. It can be seen that the method mentioned in this paper not only is theoretically comprehensive, but also has practical significance.

\section{TABLE III. RESULTS OF DIFFERENT METHODS}

\begin{tabular}{|l|l|}
\hline $\begin{array}{l}\text { Evaluation } \\
\text { method }\end{array}$ & The ranking of schemes \\
\hline Paper[14] & DMU5>DMU4>DMU3>DMU2>DMU1 \\
\hline This paper & DMU4>DMU5>DMU3>DMU2>DMU1 \\
\hline
\end{tabular}

Figure 6 is the comparison of the efficiency values evaluated by the traditional CCR-DEA and the super-efficiency DEA for the five scenarios in the example. It can be seen from the Figure 6 that when the efficiency value of the scheme is lower than 1, the efficiency value obtained using CCR-DEA and super-efficiency DEA is the same; when the scheme efficiency value is equal to or more than 1 , the efficiency value obtained by CCR-DEA is both 1 , which cannot sort the DMU4 and DMU5. In the same example, the result of super-efficiency
DEA still has a good distinction, which reflects the superefficiency DEA is more superior in this example.

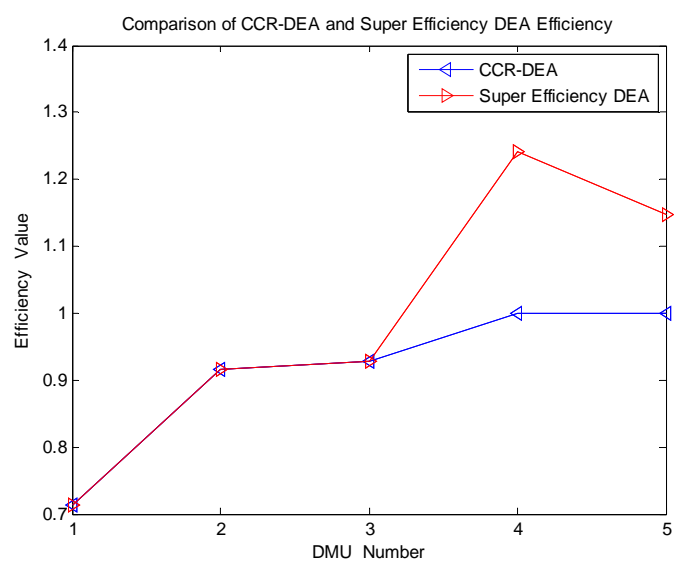

\section{FIGURE VI. COMPARISON OF CCR-DEA AND SUPER- EFFICIENCY DEA}

\section{CONCLUSION}

The innovation of this paper is that, the super-efficiency DEA was applied to the evaluation of DG access to distribution network from the perspective of reactive power optimization. The proposed scheme was proved to be feasible and objective. The case study results show that the super-efficiency DEA can be used in the evaluation of DG access to distribution network, which can effectively sort the scheme and make the result more accurate than the previous method. The evaluation method in this paper can not only reduce the active power loss of the distribution network, reduce the voltage offset, but also make the program more economical.

\section{ACKNOWLEDGMENTS}

This study was supported in part by the Major Technology Plan Project of Xiamen (3502Z2011008), and Research and Innovation Ability Training Program for Graduate Students of Huaqiao University (1511401008).

\section{REFERENCES}

[1] Li Rui, Li Yue, and Guo Wei, "Simulation Analysis of the Influence of Distributed Generation on the Reliability of Distribution Network," Power System Technology, vol. 40. , No.7, pp.2016-2021, 2016.

[2] Shen Xin, Cao Min, "Research on the Influence of Distributed Power Grid for Distribution Network," TRANSACTIONS of CHINA ELECTROTECHNICAL SOCIETY, vol.30, No.1, pp. 346-351, 2015.

[3] Yu Jian-cheng, Chi Fu-jian, and Xu Ke "Analysis of the Impact of Distributed Generation on Power Grid.," Proceedings of the CSUEPSA ,vol.24.,No.1, pp. 138-141,2012.

[4] Xia Shu, Zhou Ming, and Li Geng-yin, "Multi-objective Optimization Algorithm for Distributed Generation Locating and Sizing," Power System Technology, vol.35, No.9, pp. 115-121, 2011.

[5] CELLI G, PILO F, “Optimal Distributed Generation Allocation in MV Distribution Networks,”22nd IEEE Power Engineering Society International Conference on Power Industry Computer Applications, pp.81-86, 2001.

[6] Zheng Zhang-hua, Ai Qian, and Gu Cheng-hong, "Multi-objective Allocation of Distributed Generation Considering Environmental Factor,” Proceedings of the CSEE, vol.29, No. 13, pp. 23-28, 2009. 
[7] Li Liang, Tang Wei, and Bai Mu-ke, "Multi-objective Locating and Sizing of Distributed Generators Based on Time-sequence Characteristics," Automation of Electric Power Systems, vol.37, No.3, pp.58-63, 2013.

[8] Guo Kang, Xu Yu-qin, and Zhang Li, "Reactive power optimization of distribution network considering PV station random output," Power System Protection and Control, vol.40, No. 10, pp.53-58, 2012.

[9] Cai Yao-xing, Su Shi-ping, and Liu Gui-ying, "Reactive power optimization consider multiple objectives optimization model with distributed generators,” Electrical Measurement \& Instrumentation, vol. 52, No.8, pp.70-75, 2015.

[10] Li Mei-juan, Chen Guo-hong, "A Review on the Research and Application of DEA,” Engineering Science, vol. 6, pp.88-94, 2003.

[11] Wu Jie-kang, Tang Li-tao,and Huang Huan,“Multi-objective Economic Scheduling for Hydrothermal Power Systems Based on Genetic Algorithm and Data Envelopment Analysis," Power System Technology, vol.35,No.5,pp.76-81, 2011.

[12] Wang En-chuang, Reng Yu-long, and Zhu Chun-bo, “An Index System for Overall Efficiency Evaluation of Distribution Network Applying Three-Stage Data Envelopment Analysis,” Power System Technology ,vol.34,No.11,pp.100-105, 2010.

[13] Fu Xue-qian,Chen Hao-yong, and Liu Guo-te,"Power Quality Comprehensive Evaluation Method for Distributed Generation," Proceedings of the CSEE ,vol.34,No.25,pp.4270-4276,2014.

[14] Zhou Chun-quan, Shi Jing, and Jiang Xiang-ming, "Sitting and Sizing of Distribution Generation by Considering of Reactive Power Optimization,” Modern Electric Power,vol. 31,No. 2, pp. 42-45, 2014. 